\title{
LCA and LCC of the world's longest pier: a case study on nickel-containing stainless steel rebar
}

\author{
$\operatorname{Mark}_{\text {Mistry }}{ }^{1}\left({\text { C Christoph } \text { Koffler }^{2} \cdot \text { Sophia Wong }}^{2}\right.$
}

Received: 15 May 2015 / Accepted: 24 February 2016 / Published online: 22 March 2016

(C) The Author(s) 2016. This article is published with open access at Springerlink.com

\begin{abstract}
Purpose Built in 1941, the Progreso Pier was the first concrete structure in the world built with nickel-containing stainless steel reinforcement. The Pier has been in service for over 70 years without any significant repair or maintenance activities. The aim of this study was to understand the environmental and economic implications of selecting nickel-containing stainless steel reinforcement using the Progreso Pier as the case study.

Methods A combined environmental life cycle assessment (LCA) and life cycle costing (LCC) study was conducted. The analysis considered the potential environmental impacts and the net present cost of the stainless steel reinforced structure from cradle to grave and compared it to the same structure using conventional carbon steel.

Results and discussion The results indicated that while using stainless steel reinforcement resulted in a marginally higher environmental impact after initial construction, this is offset by the increased service life and, hence, less frequent maintenance and reconstruction activities. Relative to the as-built stainless steel reinforcement design, the environmental impacts of the carbon steel reinforced design are between 69 and $79 \%$ higher over the analysis period. Similar observations were made for the other investigated impact categories. The
\end{abstract}

Responsible editor: Chris Bayliss

Mark Mistry

mmistry@ nickelinstitute.org

1 Nickel Institute, Avenue des Arts/Kunstlaan, 13, 1210 Brussels, Belgium

2 Thinkstep, 1339 Wellington Street, Suite 203, Ottawa, ON K1Y 3B8, Canada cost implications of using stainless steel reinforcement show economic benefits that are complementary to the environmental benefits. Similar to the LCA, the service life benefits outweigh the higher unit costs for stainless steel, assuming a discount rate of $0.01 \%$ as the baseline scenario. The carbon steel reinforced design has a net present cost that is $44 \%$ higher than the as-built stainless steel reinforcement design. The crossover point for the two designs occurs at year 50, which corresponds to the reconstruction activity. A sensitivity analysis shows that the results and conclusions are sensitive to the choice in discount rate: Rates $3 \%$ and lower produce net present costs that are lower for the as-built design; rates $4 \%$ and higher produce net present costs that are lower for the alternative design.

Conclusions The study demonstrates how LCA and LCC are complementary tools that can be used in decision-making for sustainable construction. The Progreso Pier exemplifies the importance of considering the entire life cycle with service life and recycling as well as long-term life cycle impacts of infrastructure projects from an environmental and economic perspective.

Keywords LCA $\cdot$ LCC $\cdot$ Life cycle assessment $\cdot$ Life cycle costing $\cdot$ Life cycle thinking $\cdot$ Sustainable construction ·

Stainless steel

\section{Introduction}

While the life cycle assessment (LCA) of stainless steel and the life cycle cost (LCC) implications of its application have been investigated in the past (ISSF 2013; Norgate et al. 2007; SASSDA 2012; Val and Stewart 2003), a side-by-side application of both LCA and LCC based on the same, comparative case studies using consistent assumptions has been scarce so 
far. At the same time, environmental and cost considerations are important decision and performance criteria in the building and construction industry (NIST 2011; PNNL 2009; Todd and Fowler 2010). The study at hand therefore sets out to provide a combined comparative assessment using life cycle assessment and life cycle costing for the application of stainless steel as structural reinforcements in a marine environment to demonstrate the value of stainless steel products from an environmental as well as from a cost perspective. This study may then serve as a reference for future assessments of this kind and further support the communication of the benefits of nickelcontaining stainless steel to third parties.

\section{Scope of the study}

The Progreso Pier is a saltwater pier located in Yucatan, Mexico. It consists of two segments: the original pier, which is $2.1 \mathrm{~km}$ in length and was built in 1941, and a roughly $4.4 \mathrm{~km}$ additional segment, which was built in the $1980 \mathrm{~s}$. Together, the construction stretches roughly $6.5 \mathrm{~km}$ from the shore and is the longest pier in the world. The subject of this analysis is the original $2.1-\mathrm{km}$ pier, excluding the later addition. The addition is excluded due to lack of construction and inspection data (referenced reports are specific to the original span), as well as to simplify the analysis to a single construction project.

The initial scope of the study was a comparison of the Progreso Pier against a neighbouring pier. The unnamed neighbouring pier was constructed in 1969 and used carbon steel reinforcement; conversely, the Progreso Pier was initially completed in 1941 and extended in 1988, built with stainless steel reinforcements (18-8 Cr-Ni SAE 304). The carbon steel pier has since collapsed due to saltwater erosion, with only the piles remaining, while the Progreso Pier has remained functional (Fig. 1).

Saltwater erosion (exacerbated by humid climate and as well as wave and tidal action) is the most important factor in determining the life of these concrete-and-steel piers. The effectively identical environmental conditions (same high heat and humidity, seasonal hurricane-force winds, wave and tidal patterns and corresponding saltwater exposure) presented the rare opportunity to compare differing structures under matching environmental stresses. Both structures had undergone an equivalent maintenance schedule.

Yet, despite the compelling similarity in use-phase conditions, the Progreso Pier and the neighbouring pier were found to be non-comparable for the purposes of this study. Differences in function and size, as well as dissimilarities in other aspects of the pier designs, meant that functional equivalence between the two piers could not be ascertained.

For this reason, this study compares the Progreso Pier, constructed with stainless steel rebar, against an alternate, hypothetical carbon steel case study: a pier with size and function equivalent to the Progreso Pier built with carbon steel rather than stainless steel rebar. Within this report, the pier built with stainless steel rebar is referred to as the "as-built design"; the alternative with carbon steel rebar is referred to as the "alternative design."

\subsection{Functional unit and reference flows}

Ideally, the functional unit would describe the function of the pier, such as its ability to move goods, using a metric expressed as magnitude, unit, duration and level of quality (Cooper 2003; Koffler et al. 2014). However, given that the functions provided by the pier do not easily lend themselves to such a simplistic approach, the function of the Progreso Pier is determined by its intended use as defined by the designers.

The original 2-km pier finalized in 1941 was designed to accommodate two railway lines and one roadway running parallel across the full length of the pier. The pier design supports live loads associated with the operation of two 85-t, $1.5 \mathrm{~m}$ wide trains, as well as 39-t, $1.5 \mathrm{~m}$ wide, 3 -axle trucks along the length of the pier. The pier platform was designed to support a continuous distributed load of $4 \mathrm{t} / \mathrm{m}^{2}$. The piles were designed for a total allowable stress of $15 \mathrm{~kg} / \mathrm{cm}^{2}$.

The pier is composed of $17512-\mathrm{m}$ spans with massive columns and arches. The structure is concrete throughout, with steel reinforcements in structural locations under tensile or mixed load. The total volume of concrete used is 72 , $500 \mathrm{~m}^{3}$, with a mass of reinforcing steel of $220 \mathrm{t}$. The functional performance of carbon steel and stainless steel rebar is equivalent in the chosen application, with the exception of corrosion resistance. Because the structural properties are equivalent, the material content of the two piers is the same (i.e. equal amounts of steel and concrete), with the only difference being the type of steel used (stainless or carbon steel). Over the life cycle, the differences in corrosion resistance lead to more frequent maintenance and reconstruction for the alternative design.

In summary, even though there is no clear-cut quantified functional unit as such, the above approach ensured that the two pier designs were functionally equivalent and therefore fully comparable. In addition, the duration of the functional unit was chosen to be 79 years. This period is chosen to capture both the past performance (beginning in 1941) and the expected performance into the near future (through 2020). The analysis period does not correspond to expected service lives of the alternative or as-built design; rather, it is an arbitrary period that is chosen for communication purposes. The arbitrariness of the analysis period does not have a significant impact on the results due to the consideration of remaining service at the end of the analysis period. Both the LCA and LCC offer a credit at the end of life for this remaining service life, as explained in the respective sections. 
Fig. 1 Progreso Pier (right) and a neighboring pier $(l e f t)$ that collapsed

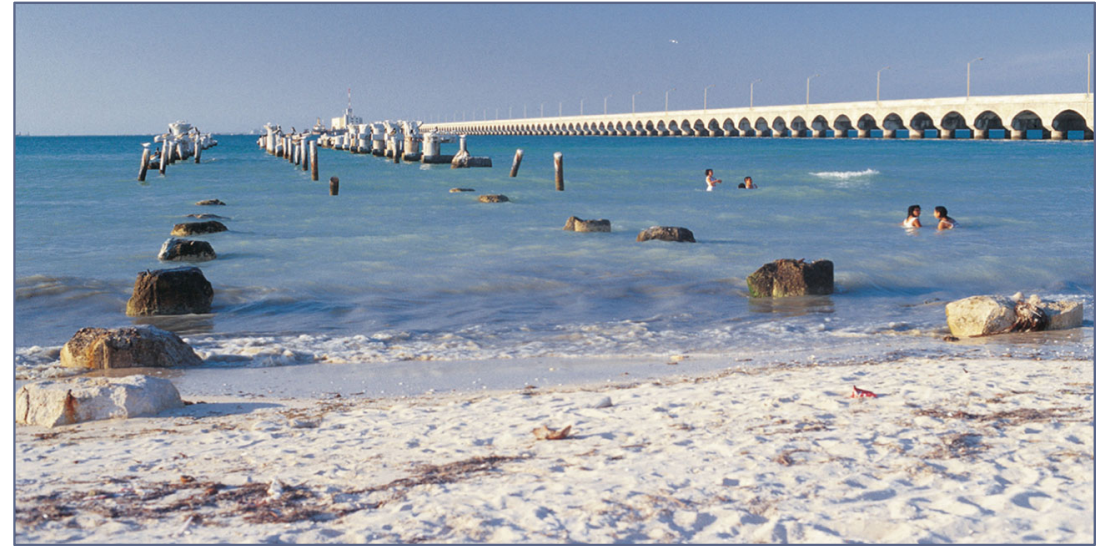

\subsection{Service life and maintenance}

For the purposes of LCA, the maintenance schedule defines the materials and activity required over the lifetime of the pier and can be a substantial contribution to the inventory of the structure. The expected service life and the maintenance requirements of designs are based on analysis conducted by CTL Group (CTL 2013) and displayed in Table 1. The service life follows the definition per US Navy's engineering command (NAVFAC), as the number of years before major restoration is necessary, given minimal maintenance to the structure during its life. Major restoration is further defined as "extensive areas that require extensive repairs using a jack hammer or other destructive means to prepare the concrete for rehabilitation" (US Navy 2012).

The maintenance schedule is based on the time for corrosion initiation and propagation of the steel. Over time, chloride ions diffuse through the concrete cover (in accordance with Fick's second law of diffusion) to the depth of the reinforcing steel. Once a critical concentration is reached, corrosion initiates and continues to propagate until repairs are required. Time to initiation and propagation is modelled using the Life-365 software (www.life-365.org). More details, including input variables, are reported in the engineering report (CTL 2013), which is available upon request from the authors of this study. For the alternative design, repairs are first required at year 10; for the as-built design, repairs are first required at year $44 .^{1}$

\footnotetext{
${ }^{1}$ Note that the modelled maintenance schedule is different than that of the actual maintenance schedule for the in situ Progreso Pier, which has not undergone any major maintenance since its construction. This difference can be attributed to the use of conservative values in this study. The engineering report listed a possible higher threshold of resistance to corrosion for stainless steel; if this value was selected, the first maintenance would occur in year 91 .
}

\subsection{System boundaries}

The system under study includes the materials, the maintenance over the life cycle, the transport of materials and the end of life of the pier. The system boundaries were selected in order to enable the effective comparison of the two designs (Fig. 2). The power consumption to operate the pier (i.e. street lighting) was excluded as it was deemed to be of little relevance and because there was no reliable data available. Due to the same reasons, temporary construction materials and processes were excluded from the system boundary. Construction-related impacts will differ between the two designs in the case of reconstruction, which will be shown to occur during the analysis period for the alternative design, but not for the as-built design. Reliable estimates for economic and environmental impacts are difficult to ascertain for construction and are thus excluded from the baseline analysis. However, due to their potential influence on the results and conclusions, sensitivity analyses are performed for construction impacts.

\subsection{Allocation}

Co-product allocation was not relevant, as co-products do not occur in pier construction. End-of-life (EOL) allocation is

Table 1 Times to corrosion initiation, and propagation and reconstruction

\begin{tabular}{lll}
\hline Activity description & Activity year & \\
\hline & Alternative design & As-built design \\
Initial construction & $0(1941)$ & $0(1941)$ \\
Maintenance \#1 & $10(1951)$ & $44(1985)$ \\
Maintenance \#2 & $25(1966)$ & $59(2000)$ \\
Maintenance \#3 & $40(1981)$ & $74(2015)$ \\
Reconstruction & $50(1991)$ & - \\
Maintenance \#1 & $60(2001)$ & - \\
Maintenance \#2 & $75(2016)$ & - \\
End of analysis period & $79(2020)$ & $79(2020)$ \\
\hline
\end{tabular}


Fig. 2 Maintenance schedule used in analysis (CTL 2013)

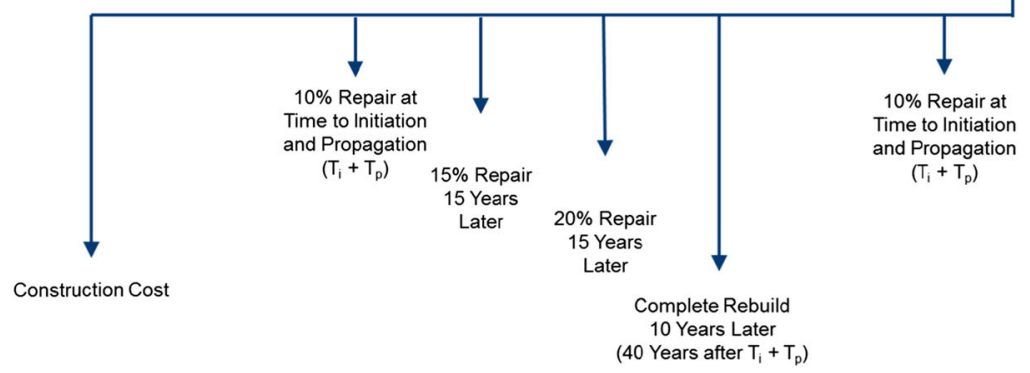

used to account for recycling of steel scrap at the end of life. The "value of scrap" approach is applied, which is essentially an avoided burden/EOL recycling allocation method that has been endorsed by the metals industry (Atherton et al. 2007). At the end of the analysis period, both the as-built and alternative designs have remaining structural service life. For both the LCC and LCA, this service life is credited back to the system in proportion to the service life remaining divided by the total service life.

\section{Life cycle inventory analysis}

The primary sources of data are a detailed inspection of the Pier conducted in 1998 (Arminox 1999) and a more recent inspection of the Pier conducted in 2006 and 2010 (TorresAcosta et al. 2006). These are engineering reports and/or peerreviewed papers and are considered to be of high quality. Data on the alternative design replicate the material quantities of the as-built design.

National and regional averages for fuel inputs and electricity grid mixes as well as for other processes such as cement and steel were obtained from the GaBi 6 database issued in 2012 ( $\mathrm{GaBi} 2013)$. All rebar is assumed to be manufactured in Europe and shipped to Progreso for use in the Pier. Cement is known to be shipped to Progreso from Denmark (76\%) and transported from undisclosed locations in the USA and Mexico (24\%); the Mexico/US cement was assumed to be transported $2000 \mathrm{~km}$ via rail. Local concrete production is assumed to occur $30 \mathrm{~km}$ away from the site, with fine and coarse aggregates available onsite.

The LCI and LCIA results indicate that transportation is small compared to other sources of impact in the Progreso Pier life cycle. The assumed distances and modes are considered reasonable approximations. Variation in the modes and distances is expected to have a negligible impact on the conclusions of this study.

\subsection{Modelling}

The life cycle of the Progreso Pier comprises four life cycle stages, including raw materials production, construction, maintenance and end-of-life (Fig. 3)

- Raw materials production: This life cycle stage comprises the impacts from raw materials of the structural elements of the Pier, such as concrete and steel reinforcement.

- Construction: This stage comprises the impacts from constructing the Pier. No data were available on the construction methods and/or energy used during construction. For this reason, construction was not included in the baseline analysis. A sensitivity analysis was performed for a range of possible construction stage impacts.

- Maintenance: This life cycle stage comprises the impacts associated with the scheduled maintenance and repairs of the Pier. Although it is documented that "there has been a complete lack of routine maintenance activities" on the Progreso Pier and that "the pier has not undergone any major repair work" (Arminox 1999), the analysis considers a maintenance schedule as per US Navy specifications (US Navy 2012).

- End-of-life: This life cycle stage comprises the impacts associated with disposal of the concrete and recycling of the steel reinforcement. Steel recycling uses the value of scrap allocation approach and assumes a $90 \%$ recovery rate.

No estimate is provided in the engineer's report for the material required for repairs; in this study, it is assumed that $50 \%$ of the steel and concrete will need to be removed and replaced within the affected area (e.g. for maintenance \#1, $50 \%$ of the steel and concrete will be removed and replaced over $10 \%$ of the Pier). This includes both the production of the replacement materials, their transportation to the construction site and the disposal or recycling of the replaced materials. At 40 years past initiation and propagation, the corrosion 
Fig. 3 Life cycle stages of Progreso Pier

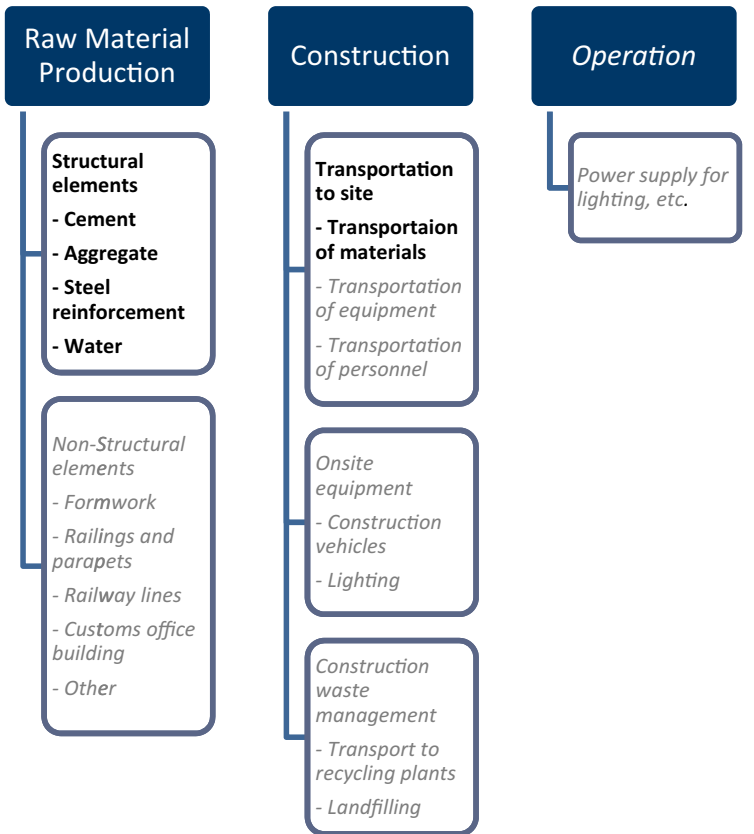

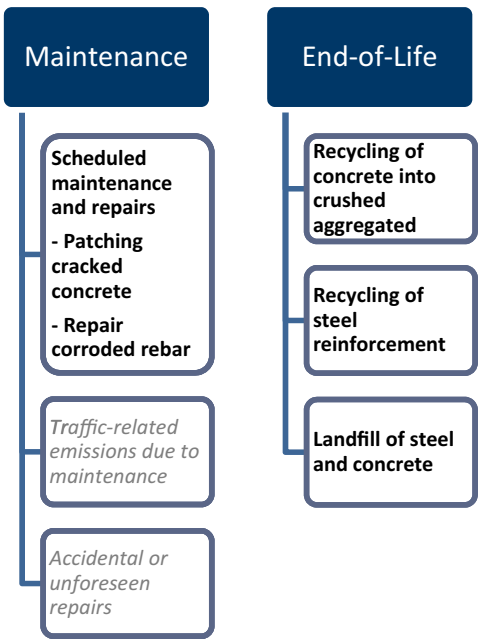

is considered to be too severe for simple repairs. In this case, a complete rebuild (i.e. reconstruction) is required.

\section{Life cycle impact assessment}

Four impact categories have been selected for this assessment, using the CML 2001 (November 2010) as the characterization methodology: acidification potential (AP), eutrophication potential (EP), global warming potential (GWP) and the photochemical oxidant creation potential (POCP). These impact categories are commonly reported in LCAs and are part of the categories recommended by the metals industry (thinkstep 2014). Other impact categories are not reported as not relevant for these investigations or not seen as being robust enough.

The LCIA impacts from the as-built and alternative designs are compared in the figure below. The alternative design has a higher total impact in all categories, ranging from $69 \%$ higher for eutrophication potential to $79 \%$ higher for the summer smog potential (Fig. 4). Given the long analysis period, it is useful to compare the results using a time series plot. This perspective provides insight into the timing of impacts, as well as the activities that influence the overall results. Figure 5 shows the time series impacts for the designs using global warming potential (other impact categories would follow a similar pattern). Note that the difference between the as-is and the alternative design is only around $3 \%$ after initial construction, as the cradle-to-gate GWP of both designs is heavily dominated by the concrete (no less than $93 \%$ across the four impact categories for the as-built scenario, no less than $98 \%$ for the alternative scenario), so the higher initial burden of the stainless steel only leads to a marginal increase in burden for the entire pier. This small difference in impact during initial construction is made up for by the early maintenance (year 10) required on the alternative design and continues to widen due to subsequent maintenance activities. The spike at year 50 is due to reconstruction; this activity is the largest contributor of the difference in impact between the two designs.

At the end of the analysis period, the as-built design has a non-negative impact due to the landfilling burden of the materials. Although not directly seen on the plot, this impact is offset by both recycling of the stainless steel rebar (at a recovery rate of $90 \%$ ) and a credit allotted to the system based on the remaining service life of the as-built design ( 5 years out of the 84-year expected service life). Conversely, the alternative design has a credit, caused primarily by the long remaining service life of the alternative design reconstruction (21 years out of the expected 50-year service life) left at the end of the analysis period.

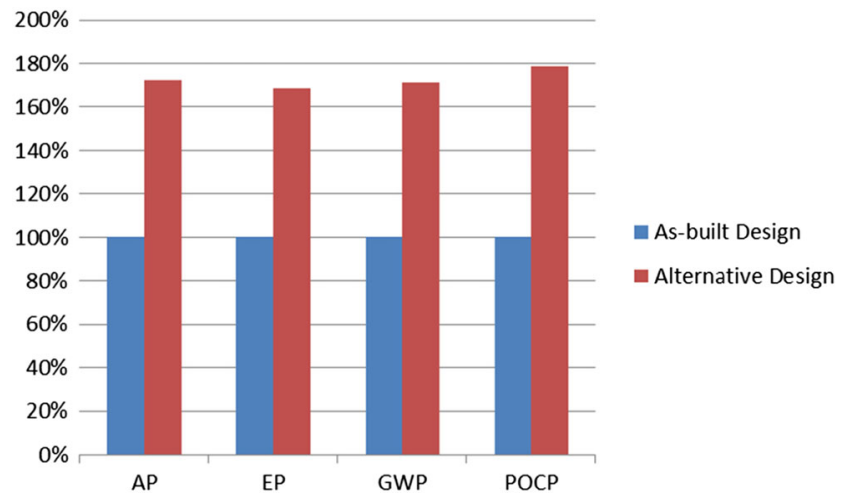

Fig. 4 Comparison of environmental impacts over the analysis period 


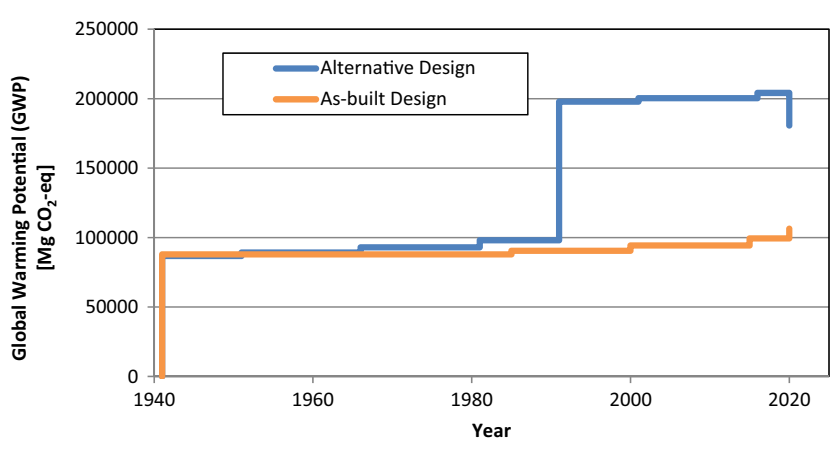

Fig. 5 Time series comparison using global warming potential

The as-built design outperforms the alternative design due to two major factors: the durability benefits of stainless steel rebar and the dominance of impacts from concrete rather than rebar.

\section{Life cycle costing}

Life cycle costing (LCC) is "used for predicting and assessing the cost performance of constructed assets" (ISO 156865:2008). Similar to its environmental counterpart (LCA), LCC considers the life cycle of a product to determine its economic impact. This typically includes initial construction, maintenance, operation and end-of-life. For the study at hand, cost information was provided by the Life-365 software (version 2.1.1) which was also used to establish the maintenance schedules and converted to 1941 dollar values using data from the United States Department of Labor Consumer Price Index (http://www.bls.gov/cpi/). Table 2 shows the cost data used in the analyses.

The fundamental relationship used to calculate total NPC is shown in the following formula:

$N P C=\sum_{n=0}^{N} \frac{C n}{(1=i)^{n}}$

where $N P C$ is the total net present cost of the Progreso Pier, $C$ are the costs incurred in year $n$, in 1941 dollars, $N$ is the analysis period, $n$ is the year in which cost occurred and $i$ is the real discount rate.

The discount rate is a key variable in the calculation of NPC. This rate reflects the time value of money. It is used to evaluate future costs in relation to present costs, accounting for the prevailing interest rate and (indirectly) the inflation rate. The discount rate is variable across time. In the USA, the White House Office of Management and Budget suggests a discount rate to be used for a given year; similar rates are established in other countries. Typical rates used by public agencies for long-term investments are between 1 and $8 \%$, with extremes ranging from 0 to nearly $14 \%$. The Society of
Table 2 Unit costs for life cycle costing analysis

\begin{tabular}{lll}
\hline & Unit cost $(2013 \$)$ & Unit cost $(1941 \$)$ \\
\hline Concrete & $\$ 100 / \mathrm{m}^{3}$ & $\$ 6.30 / \mathrm{m}^{3}$ \\
Carbon steel rebar & $\$ 0.11 / \mathrm{kg}$ & $\$ 0.01 / \mathrm{kg}$ \\
Stainless steel rebar & $\$ 6.59 / \mathrm{kg}$ & $\$ 0.42 / \mathrm{kg}$ \\
Repair & $\$ 122 / \mathrm{m}$ & $\$ 7.68 / \mathrm{m}$ \\
\hline
\end{tabular}

Environmental Toxicology and Chemistry (SETAC) recommends a $0.01 \%$ discount rate for long-term investments.

A higher discount rate means it has the effect of decreasing the NPC of future activities. This is due to the fact that interest has had time to accrue before being spent on the future investment. For civil engineering projects, future maintenance and reconstruction are highly affected by the discount rates, particularly those that occur decades in the future.

As shown in Fig. 6, the NPC of the as-built design (\$520 k) is nearly $30 \%$ less than that of the alternative design $(\$ 730 \mathrm{k})$ when using a discount rate of $0.01 \%$. The use of stainless steel rebar in the as-built design allows for a longer service life and less maintenance over the analysis period, allowing the asbuilt design to make up for the upfront investment (the asbuilt design has a $20 \%$ higher cost than the alternative design). Given the low discount rate, the future costs (i.e. maintenance and reconstruction) have a significant influence on the results.

The LCC analysis shows that the as-built design provides a lower NPC when using the SETAC suggested discount rate of $0.01 \%$. The key activity in the life cycle is the reconstruction of the alternative design at year 50 (1991). Reconstruction is the crossover point between the two designs (i.e. the year at which the initial investment in stainless steel is realized). The maintenance activities, while not negligible, are small compared to the initial construction and reconstruction activities.

\section{Sensitivity analysis}

Sensitivities are conducted for two variables: the discount rate and the construction costs. The baseline scenario assumed used a $0.01 \%$ discount rate and excluded construction costs from the system boundary. Both of these of these assumptions are potentially significant with regard to the conclusions that can be drawn from the LCC.

The results are sensitive to the choice in the discount rate. In particular, the discounting of the reconstruction cost at year 50 is highly affected given that it occurs far in the future relative to the initial construction. This is due to the exponential relationship between years and NPC (as shown in Eq. 1). Because of this relationship, when the discount rate is $4 \%$ or higher, reconstruction of the alternative design is decreased to where the initial investment of the stainless steel in the as-built 


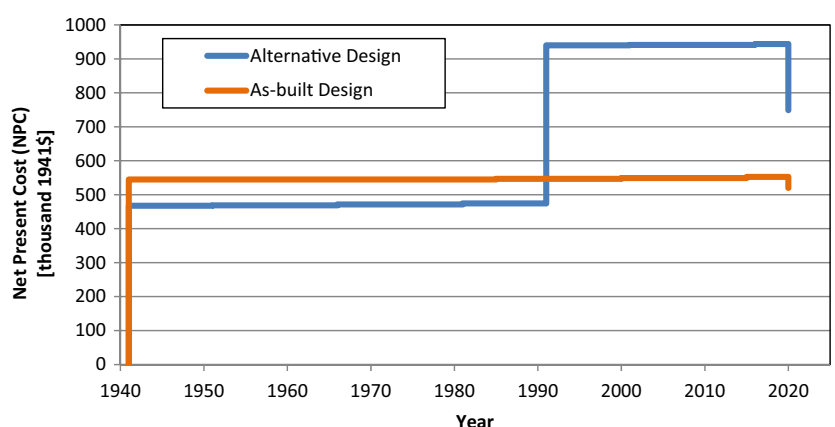

Fig. 6 Life cycle costing results (0.01\% discount rate)

design is not recouped, causing the as-built design to have a higher NPC than the alternative design (Fig. 7).

The baseline analysis only considers the materials that are used to construct the pier, whereas the true construction costs would also include the labour, overhead, profits and other costs that are part of a standard construction project. The construction costs range from $0 \%$ of the material costs (the baseline scenario, where construction costs are excluded) to $100 \%$ of materials costs (assuming that the construction costs are equal to the material costs). By including construction costs, the gap between the as-built and alternative design widens due to the increase in the reconstruction cost for the alternative design (Fig. 8).

Another relevant sensitivity analysis involves altering both the construction costs and the discount rate. The pivot point for the discount rate increases when construction costs are included. Assuming that construction costs are $100 \%$ of material costs, the pivot point occurs roughly at a $5 \%$ discount rate (as opposed to between 3 and $4 \%$ when construction costs are excluded).

\section{Data quality}

Due to the lack of historic LCI data, the implicit assumption of using current LCI data is that the average improvements in the environmental burdens of stainless steel and carbon steel-

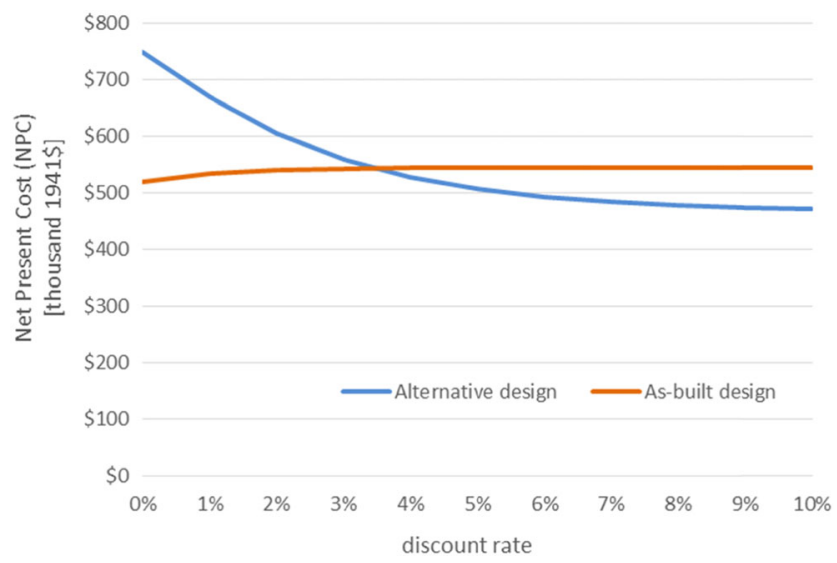

Fig. 7 Sensitivity of LCC results to the discount rate

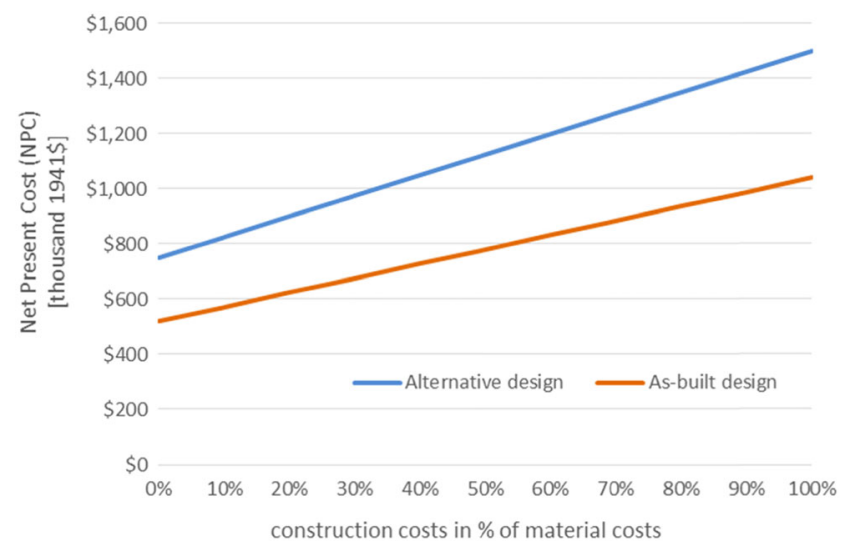

Fig. 8 Sensitivity of the LCC results to the construction costs

either due to efficiency gains (see also Dahmus 2014) or legislative requirements of the steel industry - have been generally comparable over the last 75 years or so. So, while the representativeness of the LCI data used is most likely poor with regard to the specific points in time when construction and maintenance occur, it is not expected that this error would materially affect the comparison between the two designs compared.

Other aspects of data quality such as technological representativeness, geographical representativeness, completeness and reliability are much less affected by this issue so that the overall data quality is judged to be sufficient to support the goal and scope of the study.

\section{Conclusions}

This study analysed two designs of the Progreso Pier for comparison: (1) the as-built design using stainless steel rebar, and (2) the alternative design using carbon steel rebar. The only difference between the designs is the rebar material.

The choice in rebar material has several practical impacts:

- The service life is significantly shorter for the alternative design, with more frequent maintenance.

- The unit material cost of stainless steel rebar is higher than carbon steel rebar, resulting in higher activity costs for initial construction, maintenance and reconstruction.

- The environmental impacts of stainless steel rebar are higher than carbon steel rebar, resulting in higher impacts for initial construction, maintenance and reconstruction.

The LCA demonstrated consistently (and significantly) lower potential environmental impacts for the as-built design. Since the concrete accounts for over $93 \%$ of the environmental impacts, the environmental impact differences between stainless and carbon steel have only a minor influence on the initial construction. The marginally higher impact of the asbuilt design after initial construction (3\% higher than the alternative design) is made up for over the life cycle due to 
the increased service life (and, hence, more infrequent maintenance and reconstruction activities). Relative to the as-built design, the environmental impacts alternative design are between 69 and $79 \%$ higher over the analysis period. It is concluded that the use of stainless steel rebar in the Progreso Pier is an environmentally preferable material choice.

The cost implications of using stainless steel rebar show economic benefits that are complementary to the environmental benefits. Similar to the LCA, the service life benefits outweigh the higher unit costs for stainless steel, assuming a discount rate of $0.01 \%$. The alternative design has a net present cost that is $44 \%$ higher than the as-built design. The crossover point for the two designs occurs at year 50, which corresponds to the reconstruction activity. A sensitivity analysis shows that the results and conclusions are sensitive to the choice in discount rate: rates $3 \%$ and lower produce NPCs that are lower for the as-built design; rates $4 \%$ and higher produce NPCs that are lower for the alternative design. As the discount rate is variable over time and differs between applications, industries and stakeholders, it is recommended that the results and conclusions from this LCC be communicated along with the selected discount rate.

Overall, the study finds that the use of stainless steel rebar in the Progreso Pier has significantly influenced the life cycle economic and environmental impacts of the structure. The use of carbon steel rebar would have significantly decreased the service life, causing more frequent maintenance and requiring reconstruction during the analysis period. This increased service life provides environmental benefits over the life cycle that are much higher than the burdens associated with the use of stainless steel rather than carbon steel rebar material itself. The economic benefits are also apparent when the SETACrecommended discount rate is used, though the economic case is less definitive due to the sensitivity in the discount rate.

Open Access This article is distributed under the terms of the Creative Commons Attribution 4.0 International License (http:// creativecommons.org/licenses/by/4.0/), which permits unrestricted use, distribution, and reproduction in any medium, provided you give appropriate credit to the original author(s) and the source, provide a link to the Creative Commons license, and indicate if changes were made.

\section{References}

Arminox R (1999) Pier in progreso Mexico: inspection report evaluation of the stainless steel reinforcement

Atherton J et al (2007) Declaration by the metals industry on recycling principles. Int J Life Cycle Assess 12(1):59-60

Cooper J (2003) Specifying functional units and reference flows for comparable alternatives. Int J Life Cycle Assess 8(6):337

CTL Group (2013) Service life modeling of the progreso pier

Dahmus JB (2014) Can efficiency improvements reduce resource consumption? A historical analysis of Ten activities. J Ind Ecol 18(6):883-897

$\mathrm{GaBi}$ (2013) GaBi 6 dataset documentation for the software-system and databases, LBP, University of Stuttgart and thinkstep AG, LeinfeldenEchterdingen, 2013 (http://documentation.gabi-software.com/)

ISO 15686 (2008) ISO 15686-5 Buildings and constructed assetsservice-life planning-Part 5: life-cycle costing

ISSF (2013) Life cycle inventory and analysis. International stainless steel forum, Brussels. Available at http://www.worldstainless.org/ health_and_environment/life_cycle_inventory_and_analysis

Koffler C, Geyer R, Volz T (2014) Life cycle inventory. In: Schenk R, White P (eds) Environmental Life Cycle Assessment. American Center for Life Cycle Assessment (ACLCA)

US Navy (2012) US Navy, Final report for the floating double-deck pier, TR-NAVFAC ESC-CI-1223, September

NIST (2011) Metrics and Tools for Sustainable Buildings Project. The National Institute of Standards and Technology. Available at http:// www.nist.gov/el/economics/metrics_for_sustainable_bldg.cfm. Last accessed 11/29/2015

Norgate TE, Jahanshahi S, Rankin WJ (2007) Assessing the environmental impact of metal production processes. J Clean Prod 15(8-9):838-848

PNNL (2009) Building cost and performance metrics: data collection protocol. Prepared for the Department of Energy by the Pacific Northwest National Laboratory. Available at https://www1.eere.energy.gov/femp/ pdfs/datacollectionprotocol.pdf. Last accessed 11/29/2015

SASSDA (2012) Life cycle costing and stainless steel. Southern Africa Stainless Steel Development Association. Available at http://sassda. co.za/about-stainless/life-cycle-costing-and-stainless-steel/. Last accessed 11/29/2015

Thinkstep AG (2014) Harmonization of LCA methodologies for metals; Version 1.01

Todd JA, Fowler KM (2010) Measuring performance of sustainable buildings. Whole building design guide. Available at https://www.wbdg. org/resources/measperfsustbldgs.php. Last accessed 11/29/2015

Torres-Acosta AA, Castro-Borges P, Moreno EI, Cuadros-Abad HD (2006) Structural evaluation and rehabilitation of concrete arches in the Progreso pier. Bridge Maintenance, Safety, Management and Life-Cycle Optimization, Taylor \& Francis Group, London

Val DV, Stewart MG (2003) Life-cycle cost analysis of reinforced concrete structures in marine environments. Struct Saf 25(4):343-362 